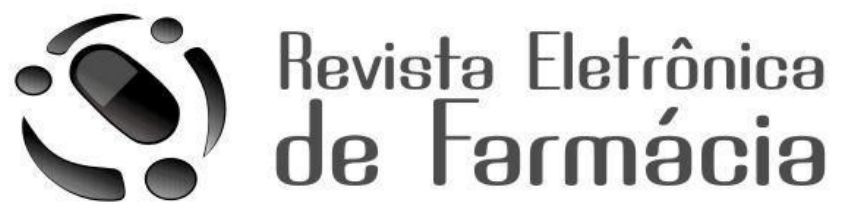

REF-ISSN1808-0804 Vol.XI (2),01-14, 2014.

\title{
PROSPECÇÃO FITOQUÍMICA, TEOR DE FLAVONOIDES TOTAIS E CAPACIDADE ANTIOXIDANTE DE Campomanesia xanthocarpa Mart. ex O. Berg (MYRTACEAE)
}

PHYTOCHEMICAL SCREENING, TOTAL FLAVONOIDS CONTENT AND ANTIOXIDANT CAPACITY OF Campomanesia xanthocarpa Mart. ex $O$. Berg (MYRTACEAE)

TAMIZAJE FITOQUÍMICO, FLAVONOIDES TOTALES Y CAPACIDAD ANTIOXIDANTE DE Campomanesia xanthocarpa Mart. ex O. Berg (MYRTACEAE)

Simone Yae Abe, Sayonara Mendes Silva, João Carlos Possamai, Tomoe Nakashima.

Recebido em 07/09/2012, Aceito em 27/03/2014.

RESUMO: A espécie Campomanesia xanthocarpa Mart. ex. O. Berg é popularmente conhecida como guabiroba e pertence à família Myrtaceae. Há relatos na literatura da presença de polifenois nas folhas. O objetivo do trabalho foi avaliar a capacidade antioxidante das frações do extrato hidroalcoólico das folhas de C. xanthocarpa em microplacas e proceder ao doseamento de flavonoides totais, além disso, realizar a prospecção fitoquímica. A análise qualitativa indicou a presença de flavonoides, antraquinonas, esteroides e/ou triterpenoides, heterosídeos antociânicos, saponinas, taninos, amino grupos e ácidos fixos. O teor de flavonoides totais foi de $1,00 \%$. Com relação à capacidade antioxidante avaliada pelo $\mathrm{DPPH}$, a fração acetato de etila apresentou $\mathrm{CE}_{50}$ de $91,8 \mu \mathrm{g} / \mathrm{mL}$ e a butanólica, $98,16 \mu \mathrm{g} / \mathrm{mL}$, 
resultados melhores do que o da rutina, padrão positivo, cujo $\mathrm{CE}_{50}$ foi de 121,06 $\mu \mathrm{g} / \mathrm{mL}$. Considerando os resultados, pode-se dizer que as folhas de C. xanthocarpaapresentam metabólitos com capacidade antioxidante relevante e teor de flavonoides condizentes com o de outras espécies da família Myrtaceae. A determinação da capacidade antioxidante em microplacas se mostrou vantajosa em relação à técnica original, devido à redução nas quantidades de solventes, amostras e reagentes empregados.

PALAVRAS-CHAVE: Campomanesia xanthocarpa, DPPH, microplacas

ABSTRACT: The species Campomanesia xanthocarpa Mart. ex. O. Berg is popularly known as guabiroba and belongs to the family Myrtaceae. There are published reports of the presence of polyphenols in the leaves. The objective of this study was to evaluate the antioxidant capacity of fractions of the hydroalcoholic extract of the leaves of C. xanthocarpa in microplates and proceeding to the measurement of total flavonoids. In addition, it was performed the phytochemical screening. Qualitative analysis indicated flavonoids, anthraquinones, steroids and/or triterpenoid, heterosides anthocyanin, saponins, tannins, fixed acids and amino groups. The total flavonoid content was $1.00 \%$. With regard to antioxidant activity, the ethyl acetate fraction showed $\mathrm{EC}_{50}$ of $91.8 \mathrm{mg} / \mu \mathrm{L}$ and butanol, $98.16 \mathrm{mg} / \mu \mathrm{L}$, better results than of rutin, positive pattern, whose $\mathrm{EC}_{50}$ was $121.06 \mathrm{mg} / \mu \mathrm{L}$. Considering the results, the leaves of C. xanthocarpa have metabolites with antioxidant capacity and the flavonoids content is simillar to the other species of the family Myrtaceae. Evaluation of antioxidant capacity in microplates showed advantages over the original technique, due the reduced amounts of solvents, samples and reagents used.

KEYWORDS: Campomanesia xanthocarpa, DPPH, microplates

RESUMÉN: La especie Campomanesia xanthocarpa Mart. ex O. Berg es conocido popularmente como guabiroba y pertenece a la familia Myrtaceae. Hay informes en la literatura para la presencia de polifenoles en las hojas. El objetivo de este estudio fue evaluar la capacidad antioxidante de las fracciones del extracto hidroalcohólico de las hojas de C. xanthocarpa en microplacas y proceder a la medición de flavonoides totales. Además, realizar el tamizaje fitoquímico. El análisis cualitativo indicaba la presencia de flavonoides, antraquinonas, esteroides o triterpenoides, heterósidos antocianina, saponinas, taninos, ácidos fijado y grupos amino. El contenido total de flavonoides fue de $1,00 \%$. Con respecto a la actividad antioxidante, la fracción de acetato de etilo mostró $\mathrm{CE}_{50}$ de $91,8 \mathrm{mg} / \mu \mathrm{l}$ y butanol, 
$98,16 \mathrm{mg} / \mu \mathrm{l}$, mejores resultados que la de rutina, patrón positivo, cuya $\mathrm{CE}_{50}$ fue $121,06 \mathrm{mg} / \mu \mathrm{l}$. Considerando los resultados, se puede decir que el hojas del C. xanthocarpa tienen metabolitos con el capacidad antioxidante y el contenido de flavonoides es coherente con otras especies de la familia Myrtaceae. Evaluación de la capacidad antioxidante en microplacas demostrado ser ventajoso relativo en la técnica original, debido a cantidades reducidas de disolventes, las muestras y los reactivos empleados.

PALABRAS CLAVES: Campomanesia xanthocarpa, DPPH, microplacas

\section{INTRODUÇÃO}

O emprego de plantas para fins medicinais é uma das mais antigas formas de prática medicinal da humanidade e, apesar da evolução dos fármacos sintéticos, as fontes naturais continuam sendo muito usadas pela população ${ }^{(1,2)}$.

A espécie Campomanesia xanthocarpa Mart. ex O. Berg é popularmente conhecida por gabiroba ou guabiroba e pertence à família Myrtaceae. $\mathrm{Na}$ medicina popular, seu uso é indicado para inúmeras patologias como diarreia, reumatismo, altos níveis de colesterol e triglicerídeos, obesidade, úlcera gástrica, cistites e uretrites $^{(3,4)}$. No extrato das folhas é indicada a presença de flavonoides, taninos e saponinas $^{(5)}$, sendo a quercetina, miricitrina e rutina alguns dos flavonoides descritos ${ }^{(6)}$.

Os principais radicais livres produzidos no organismo são derivados do metabolismo do oxigênio, os quais são neutralizados por um poderoso sistema de defesa antioxidante formado por enzimas como a superóxido dismutase, glutationa e catalase. Apesar disso, pode haver excesso dessas espécies reativas, cujo acúmulo está relacionado ao desenvolvimento de doenças crônico-degenerativas. Alguns compostos naturais como ácido ascórbico, vitamina $\mathrm{E}$, polifenois, selênio e carotenoides podem agir como antioxidantes e podem retardar ou inibir o início ou a propagação de uma reação oxidativa em cadeia e, então, prevenir ou reparar os danos causados pelo oxigênio às células ${ }^{(7)}$.

A avaliação da capacidade antioxidante pela reatividade contra o DPPH é uma metodologia amplamente difundida. No entanto, emprega quantidades razoavelmente grandes de solventes orgânicos, reagentes de alto custo e amostras. Considerando o atual apelo pela redução na geração de resíduos visando à preservação do meio ambiente, optou-se por modificar a 
técnica original, transpondo-a para microplacas de 96 poços, reduzindo, assim, a um décimo as quantidades de reagentes e amostras utilizadas.

Tendo em vista que flavonoides e taninos são classes de polifenois que apresentam reconhecido papel na

\section{MATERIAL E MÉTODOS}

Material botânico

As folhas de $C$. xanthocarpa foram coletadas em abril de 2009 no Setor de Ciências Agrárias da Universidade Federal do Paraná em Curitiba, PR. O material vegetal foi seco à temperatura ambiente e à sombra durante sete dias para a posterior realização das pesquisas.

Extrato hidroalcoólico para a prospecção fitoquímica

O extrato hidroalcoólico foi preparado a partir de $20,09 \mathrm{~g}$ de folhas secas e fragmentado de $C$. xanthocarpa através do método de extração por maceração a temperatura moderada $\left(60^{\circ} \mathrm{C}\right)$ até exaustão. Como solventes extratores foram empregados etanol P.A. 100\%, etanol $70 \%(\mathrm{v} / \mathrm{v})$, etanol $50 \%(\mathrm{v} / \mathrm{v})$ e água destilada. Os extratos foram reunidos e concentrados em aparelho rotaevaporador para a eliminação do etanol e para a subsequente partição neutralização ou sequestro de radicais livres, objetivou-se avaliar a capacidade antioxidante do extrato das folhas de C. xanthocarpa e proceder ao doseamento de flavonoides totais.

com solventes de polaridades crescentes.

O extrato concentrado foi particionado sequencialmente com hexano, clorofórmio, acetato de etila, n-butanol e ao extrato remanescente foi adicionado etanol $70 \%(\mathrm{v} / \mathrm{v})$. Ao final do processo foram obtidas cinco frações: hexânica, clorofórmio, acetato de etila, butanólica e hidroalcoólica.

EXTRATO AQUOSO PARA A PROSPECÇÃO FITOQUÍMICA

A pesquisa de metabólitos hidrossolúveis foi realizada com o extrato aquoso, o qual foi preparado por meio de maceração a quente (600 C), a partir de $40 \mathrm{~g}$ de folhas secas e fragmentadas de $C$. xanthocarpa e $200 \mathrm{~mL}$ de água destilada por $2 \mathrm{~h}$.

ENSAIOS DA PROSPECÇÃO FITOQUÍMICA

Os ensaios da prospecção fitoquímica foram realizados com as frações hexânica, clorofórmio, acetato de etila, hidroalcoólica e com o extrato aquoso ${ }^{(8)}$. 


\section{DOSEAMENTO DE FLAVONOIDES TOTAIS}

O doseamento de flavonoides totais $^{(9)}$ foi realizado em triplicata com folhas secas e pulverizadas de $C$. xanthocarpa. Foram colocados $0,3 \mathrm{~g}$ do material em balão de fundo chato contendo soluções de hexametilenotetramina $0,5 \%(1 \mathrm{~mL})$, solução de $\mathrm{HCl} 25 \%$ (2 mL) e acetato de etila $(20 \mathrm{~mL})$. Os flavonoides foram extraídos com essa solução sob aquecimento em sistema de refluxo por 30 minutos, seguido de resfriamento e filtração. O resíduo obtido da extração foi tratado com acetona $(20 \mathrm{~mL})$ por duas vezes, em sistema de refluxo (10 minutos cada). Os filtrados foram reunidos e $o$ volume ajustado para $100 \mathrm{~mL}$ com acetona. Desse, uma alíquota $(20 \mathrm{~mL})$ foi particionada com água $(30 \mathrm{~mL})$ e acetato de etila $(4 \times 10 \mathrm{~mL})$. Após descarte da fase aquosa, a fase orgânica foi transferida para balão volumétrico de $50 \mathrm{~mL}$, ajustando-se o volume com acetona, obtendo-se a solução $A$.

Solução teste: transferiu-se uma alíquota de $10 \mathrm{~mL}$ da solução A para balão volumétrico de $25 \mathrm{~mL}$ contendo solução de cloreto de alumínio (1 mL). O volume foi ajustado com ácido acético glacial em metanol a $5 \%$ (v/v). Após 30 minutos de repouso, procedeu-se a leitura da absorbância da solução teste em 422 nm em relação ao branco (10 mL da solução A e $15 \mathrm{~mL}$ de ácido acético glacial em metanol), em Espectrofotômetro Ultravioleta Shimadzu UV 1601. O teor de flavonoides totais foi determinado segundo a fórmula abaixo:

$\%$ flavonoides $=(A \times 1,25) / \mathrm{m}$ Onde:

A: absorvância em 422 nm

m: massa da amostra em gramas

PREPARO DAS AMOSTRAS PARA A AVALIAÇÃO DA CAPACIDADE ANTIOXIDANTE Primeiramente foi preparado um extrato bruto a partir de $40 \mathrm{~g}$ de folhas secas e fragmentadas de C. xanthocarpa e $1000 \mathrm{~mL}$ de etanol $70 \%(\mathrm{v} / \mathrm{v})$ pela técnica de turbólise. 0 extrato foi concentrado em rotaevaporador para a eliminação do etanol. Esse extrato foi particionado em funil de separação de forma sequencial com éter de petróleo, clorofórmio, acetato de etila e nbutanol. O restante do extrato bruto após o fracionamento foi denominado fração remanescente.

\section{AVALIAÇÃO DA CAPACIDADE ANTIOXIDANTE}

Primeiramente, foi realizada a avaliação qualitativa da capacidade antioxidante $^{(10)}$. Alíquotas de $1 \mathrm{~mL}$ das frações éter de petróleo, clorofórmio, acetato de etila, butanólica e "remanescente", obtidas 
a partir do extrato bruto, foram levadas à secura em banho-maria a $40^{\circ}$ C. Os resíduos de cada fração foram ressuspensos em $100 \mu \mathrm{L}$ de metanol. A partir dessas soluções procedeu-se uma cromatografia em camada delgada - CCD, empregando a rutina como padrão positivo. A placa de CCD foi eluída em fase móvel constituída por clorofórmio/metanol $(9: 1 ; \mathrm{v} / \mathrm{v})$ e revelada com uma solução de DPPH a 0,4 mM em metanol.

Uma curva de calibração da solução de DPPH foi construída para os cálculos de \% de atividade antioxidante e \% de DPPH remanescente ${ }^{(10)}$. Para tanto, uma solução estoque de DPPH na concentração de $40 \mu \mu \mathrm{g} / \mathrm{mL}$ foi preparada com metanol. A partir dessa, foram feitas diluições com metanol para a obtenção de soluções de DPPH nas seguintes concentrações: $1,5,10,15,20,25$, 30, $35 \mu \mathrm{g} / \mathrm{mL}$. Em triplicata, $300 \mu \mathrm{L}$ de cada concentração foram transferidos para uma microplaca de 96 poços e a leitura realizada a 540 nm em Fotômetro de Microplacas Multiskan FC Thermo Scientific.

A avaliação quantitativa da capacidade antioxidante das folhas de C. xanthocarpa se deu a partir de soluções metanólicas das frações do extrato bruto. Para a preparação das amostras, $10 \mathrm{~mL}$ das frações clorofórmio, acetato de etila, butanólica e "remanescente" foram levadas a secura em banho-maria a $40^{\circ} \mathrm{C}$. Essas foram ressuspensas em metanol com quantidade suficiente para a solubilização do resíduo e diluído até a concentração de 500 $\mu \mathrm{g} / \mathrm{mL}$ (solução mãe). A partir das soluções mãe foram realizadas diluições para a obtenção de amostras nas concentrações de 10, 25, 50, 100, 150, $200 \mu \mathrm{g} / \mathrm{mL}$. Empregou-se rutina e ácido ascórbico como controles positivos nas mesmas concentrações das amostras. Como branco, utilizouse $30 \mu \mathrm{L}$ das amostras ou controles positivos e $270 \mu \mathrm{L}$ de metanol.

A determinação da capacidade antioxidante foi realizada em microplacas de poliestireno com 96 poços. A $30 \mu \mathrm{L}$ das amostras ou controles positivos foram adicionados $270 \mu \mathrm{L}$ de solução metanólica de DPPH a $40 \mu \mathrm{g} / \mathrm{mL}$. Após 30 minutos do início da reação, realizou-se a leitura das absorbâncias do complexo (amostra ou controle positivo + DPPH) em fotômetro para microplacas a um comprimento de onda de 540 $\mathrm{nm}$.

Para a avaliação da capacidade antioxidante das diferentes amostras, calculou-se a quantidade de espécies antioxidantes necessárias para decrescer a concentração inicial de DPPH em 50\%, denominada concentração eficiente $\left(\mathrm{CE}_{50}\right)$. Curvas 
de primeira ordem foram construídas para cada amostra/controle positivo a partir de suas concentrações versus percentagem de DPPH remanescente correspondente. A \% DPPH remanescente foi calculada de acordo com a fórmula abaixo. Cada curva obtida deu origem a uma equação da reta, cujo y foi substituído por 50 para a obtenção do $\mathrm{CE}_{50}$.

$\%$ DPPH remanescente = $[\mathrm{DPPH}]_{\mathrm{t}=30 \mathrm{~min}} /[\mathrm{DPPH}]_{\mathrm{t}=0} \times 100$

Onde:

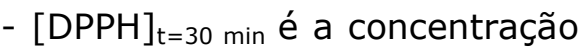
de DPPH após 30 minutos de reação;

- $[D P P H]_{t=0}$ é a concentração de DPPH no tempo zero.

O cálculo da concentração de DPPH no tempo 30 minutos é realizado através da substituição do $\mathrm{x}$ da equação da reta da curva de calibração de DPPH pelas absorbâncias obtidas após 30 minutos de reação. A concentração inicial de DPPH é determinada através da substituição do $x$ da equação da reta da curva de calibração pela absorbância da solução estoque de DPPH no tempo zero.

As percentagens de atividade antioxidante dos controles positivos e

\section{RESULTADOS E DISCUSSÃO}

PROSPECÇÃO FITOQUÍMICA de todas as amostras nas concentrações de 10, 25, 50 e $100 \mu \mathrm{g} / \mathrm{mL}$ (as concentrações menores são mais viáveis para a análise) foram calculadas no tempo de 30 minutos segundo a seguinte fórmula.

$\% \quad A A=\left\{\left[\right.\right.$ Abs $_{\text {controle }}-$ $\left.\left.\left(A b s_{\text {amostra }}-A b s_{\text {branco }}\right)\right] \times 100\right\} / A b_{\text {controle }}$ Onde:

- Abs $_{\text {controle é a absorbância }}$ inicial da solução metanólica de DPPH;

- Absamostra é a absorbância da mistura de DPPH e amostra após 30 minutos de reação;

- Abs branco é a absorbância da mistura amostra e metanol.

Análise Estatística

A análise estatística foi realizada pela aplicação do método ANOVA para o estudo de cinco tratamentos em três repetições no delineamento inteiramente casualizado com intuito de constatar se existia diferenças entre os tratamentos. Após a análise do F-teste foi constatado que há diferenças ao nível de 99\%. Sendo assim, aplicou-se 0 teste de comparação de médias - Teste de Tukey.

As análises qualitativas dos bioativos apresentaram resultado positivo para heterosídeos flavônicos e antraquinônicos, esteroides e/ou 
triterpenoides,

heterosídeos

antociânicos e saponínicos, taninos, amino grupos e ácidos fixos. Estudos realizados com folhas

de Campomanesia

xanthocarpa indicaram a presença de flavonoides, taninos, saponinas e óleo essencial ${ }^{(5)}$, condizendo com 0 resultado obtido. Outras fontes também relatam a presença dos mesmos metabólitos encontrados nesse trabalho(11).

As diferenças encontradas nos metabólitos de planta de uma mesma espécie se devem a inúmeros fatores, como a sazonalidade, o tipo de solo no qual a planta foi cultivada, disponibilidade hídrica, oferta de nutrientes, sais minerais, ritmo circadiano, fase de desenvolvimento, temperatura, radiação ultravioleta, altitude, indução por estímulos mecânicos ou ação de patógenos ${ }^{(12)}$.

A positividade na triagem fitoquímica para flavonoides e taninos e relatos na literatura da presença de flavonoides como a quercetina, miricitrina e rutina no extrato das folhas de $C$. xanthocarpa ${ }^{(6)}$ motivou a avaliação da capacidade antioxidante, uma vez que os polifenois estão entre os principais responsáveis por tal atividade em espécies vegetais.

\section{DOSEAMENTO DE FLAVONOIDES TOTAIS}

A porcentagem de flavonoides totais encontrados para as folhas secas e pulverizadas de $C$. xanthocarpa foi de 1,00\%. Esse valor é comparativo ao de outras espécies da família Myrtaceae, como a Pitangueira (Eugenia uniflora L.), cujas folhas secas devem conter, no mínimo, $1,00 \%$ de flavonoides totais $^{(13)}$.

\section{AVALIAÇÃO DA CAPACIDADE ANTIOXIDANTE}

$\mathrm{Na}$ análise qualitativa, as substâncias antioxidantes, após a revelação com o DPPH, aparecem como manchas amarelas sobre fundo púrpuro na placa de $C C D$, podendo ser observado na Figura 1, somente a fração éter de petróleo não apresentou potencial capacidade antioxidante, por isso tal fração não passou por análise quantitativa. 


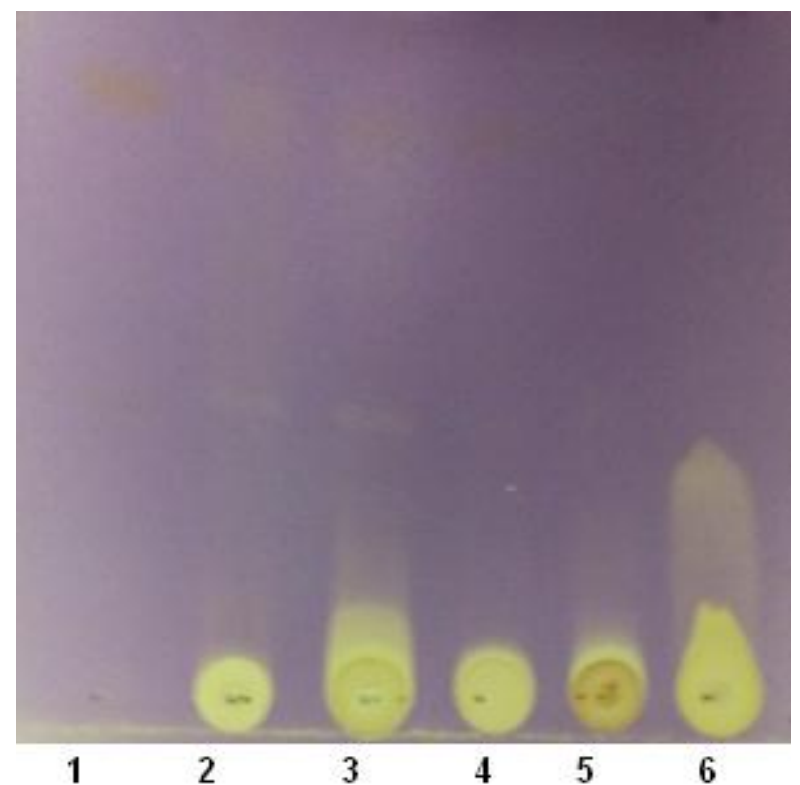

Figura 1 - Placa de CCD após a revelação com solução de DPPH. 1 - Fração éter de petróleo, 2 - Fração clorofórmio, 3 - Fração acetato de etila, 4 - Fração butanol, 5 - Fração "remanescente", 6 - rutina

A partir dos resultados da avaliação qualitativa procedeu-se à quantificação da capacidade antioxidante das frações clorofórmio, acetato de etila, butanol e "remanescente" do extrato bruto das folhas de C. xanthocarpa através do método DPPH. Como controles positivos foram empregados a rutina e o ácido ascórbico nas mesmas concentrações das amostras.

O método do DPPH baseia-se no descoramento de uma solução cor violeta de um radical livre estável quando da adição de substâncias que podem ceder um átomo de hidrogênio(14), ou seja, baseia-se na transferência de elétrons de um composto antioxidante para um oxidante. Tal metodologia utiliza quantidades relativamente elevadas de reagentes, padrões e amostras. Dentre esses, está o DPPH, um reagente de elevado custo. Além disso, apresentam limitações em relação ao número de análises simultâneas passíveis de serem realizadas, devido à necessidade de leitura das absorbâncias após tempo determinado(15).

A curva de calibração de DPPH foi construída no Microsoft Excel $®$ a partir das absorbâncias em 540 nm das soluções de DPPH e de suas respectivas concentrações em $\mu \mathrm{g} / \mathrm{mL}$. A equação de reta $\mathrm{y}=30.381 \mathrm{x}+$ 0,5356 e $R^{2}=0,987$ obtida foi empregada para o cálculo da \% DPPH remanescente, uma vez que a 
substituição do x pela absorbância resulta na concentração de DPPH.

As quatro frações avaliadas quanto à capacidade antioxidante apresentaram atividade, em maior ou menor grau (Gráfico 1). Correlacionando a Tabela 1 e o Gráfico 1, pode-se observar que quanto maior a capacidade antioxidante da amostra, menor o valor determinado para $\mathrm{O} \mathrm{CE}_{50}$. As amostras que apresentaram estatisticamente os melhores resultados foram a acetato de etila, com $\mathrm{CE}_{50}$ de $91,8 \mu \mathrm{g} / \mathrm{mL}$, e a fração butanólica, com $\mathrm{CE}_{50}$ de 98,16 $\mu \mathrm{g} / \mathrm{mL}$. A capacidade de sequestrar radicais livres dessas frações foi significantemente superior a da rutina, um flavonoide com reconhecida atividade antioxidante, o qual apresentou $\mathrm{CE}_{50}$ de $121,06 \mu \mathrm{g} / \mathrm{mL}$. Apresentaram $\mathrm{CE}_{50}$ comparável ao do ácido ascórbico, um potente agente antirradicalar (Tabela 2).

Tabela 1 - Concentração eficiente para reduzir em $50 \%\left(\mathrm{CE}_{50}\right)$ a quantidade inicial de DPPH comparados à rutina

\begin{tabular}{lll}
\hline & AMOSTRA & $\mathrm{CE}_{50}(\mu \mathrm{g} / \mathrm{mL}) \pm \mathrm{DP}$ \\
\hline \multirow{3}{*}{ Frações } & Clorofórmio & $334,34 \pm 0,21^{\mathrm{d}}$ \\
& Remanescente & $178,23 \pm 2,97^{\mathrm{c}}$ \\
& Butanol & $98,16 \pm 1,92^{\mathrm{a}}$ \\
Controle & Acetato de etila & $91,80 \pm 1,30^{\mathrm{a}}$ \\
& Rutina & $121,06 \pm 2,71^{\mathrm{b}}$
\end{tabular}

DP: desvio padrão. As médias que correspondem às mesmas letras (a, b, c, d) não diferem estatisticamente pelo teste de Tukey $(p<0,01)$, em relação ao controle rutina.

Tabela 2 - Concentração eficiente para reduzir em 50\% $\left(\mathrm{CE}_{50}\right)$ a quantidade inicial de DPPH comparados ao ácido ascórbico

\begin{tabular}{lll}
\hline & AMOSTRA & $\mathrm{CE}_{50}(\mu \mathrm{g} / \mathrm{mL}) \pm \mathrm{DP}$ \\
\hline \multirow{2}{*}{ Frações } & Clorofórmio & $334,34 \pm 0,21^{\mathrm{d}}$ \\
& Remanescente & $178,23 \pm 2,97^{\mathrm{c}}$ \\
& Butanol & $98,16 \pm 1,92^{\mathrm{b}}$ \\
Controle & Acetato de etila & $91,80 \pm 1,30^{\mathrm{b}}$ \\
\hline
\end{tabular}


DP: desvio padrão. As médias que correspondem às mesmas letras ( $a, b, c$, d) não diferem estatisticamente pelo teste de Tukey $(p<0,01)$, em relação ao controle ácido ascórbico.

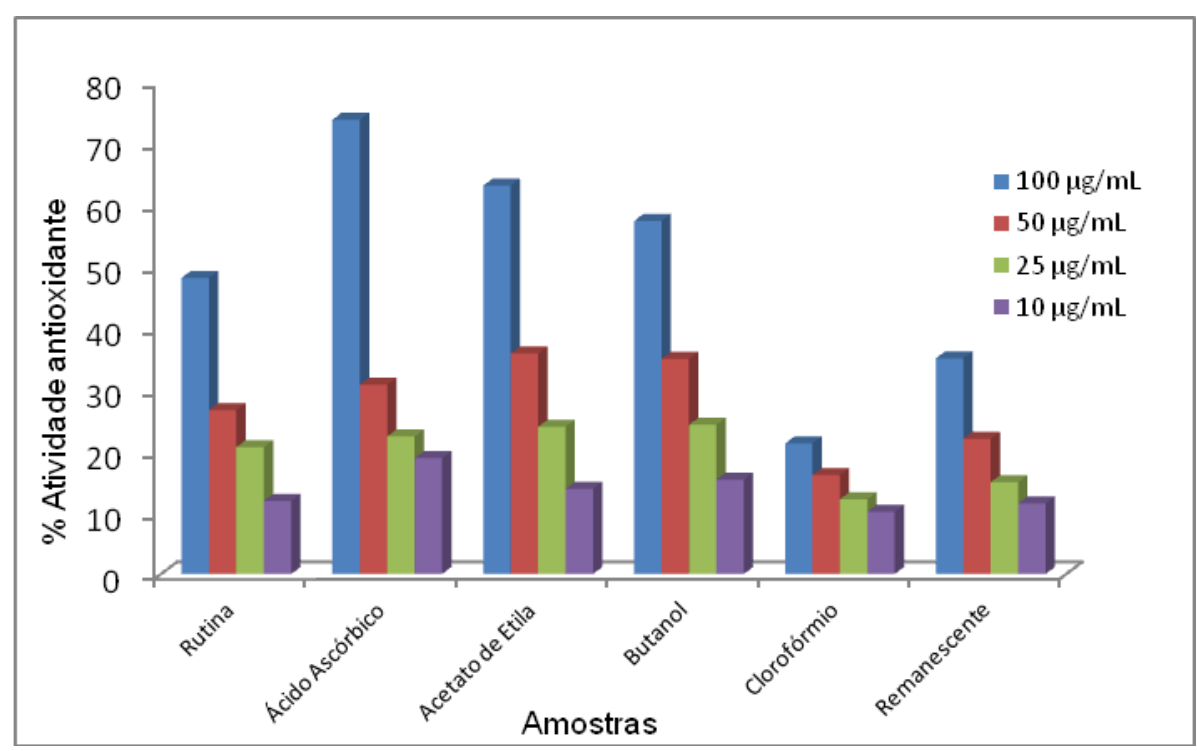

Gráfico 1 - Percentagem de atividade antioxidante das amostras e dos controles positivos após 30 minutos de reação

As frações clorofórmio e "remanescente" apresentaram atividade reduzida quando comparadas às outras e aos padrões positivos. De acordo com Barbosa ${ }^{(16)}$, as frações clorofórmica e hexânica das folhas de C. lineatifolia apresentaram menores poderes sequestradores de radicais livres em relação às frações acetato de etila e butanólica.

Considerando esses inconvenientes, optou-se por modificar a metodologia empregandose microplacas de poliestireno com capacidade de $350 \mu \mathrm{L}$ /poço. Com isso, as quantidades de reagentes, solventes e amostras foram reduzidas a um décimo em relação à metodologia original. No método tradicional o volume total é de $3 \mathrm{~mL}$, sendo $2,7 \mathrm{~mL}$ de solução de DPPH e $0,3 \mathrm{~mL}$ de amostra. A adaptação permitiu que fossem empregados somente $270 \mu \mathrm{L}$ da solução do radical livre DPPH e $30 \mu \mathrm{L}$ de amostra. A metodologia adaptada proporcionou a realização simultânea de análises de várias amostras e padrões em uma só placa. Rapidez e menor esforço do analista foram outras vantagens observadas, uma vez que o aparelho leu simultaneamente as absorbâncias dos 96 poços e transferiu os resultados para planilhas.

Os resultados condizem com os de Barbosa(16), os quais indicaram 
pronunciada atividade antioxidante das frações acetato de etila e butanólica das folhas de Campomanesia lineatifolia Ruiz e Pav. Segundo Coutinho et al. ${ }^{(17)}$, obtiveram alta capacidade antioxidante a partir da fração acetato de etila das folhas de $C$. adamantium. Cardoso et

$\begin{array}{lcr}\text { al. }{ }^{(18)} \text { relataram } & \text { a } & \text { atividade } \\ \text { antirradicalar } & \text { das } & \text { folhas }\end{array}$
de Campomanesia pubescens, alcançando $\mathrm{CE}_{50}$ de $880 \mu \mathrm{g} / \mathrm{mL}$ e $1780 \mu \mathrm{g} / \mathrm{mL}$ no extrato hexânico pelos métodos beta-caroteno/ácido linoléico e DPPH, respectivamente.

O fato das amostras acetato de etila e butanólica apresentarem melhores resultados frente ao radical livre DPPH se deve a afinidade dos

\section{CONCLUSÃO}

Os resultados das análises qualitativas foram similares aos encontrados na literatura, sendo que a presença de polifenois motivou à determinação da capacidade antioxidante das folhas de C.xanthocarpa.

O teor de flavonoides totais nas folhas de guabiroba foi condizente com o de outras espécies da família Myrtaceae.

$\mathrm{Na}$ determinação da capacidade antioxidante das folhas de C. xanthocarpa, pelo método DPPH em microplacas, verificou-se que a polifenois por esses solventes e consequente acúmulo nessas frações. De acordo com Andrade et al. ${ }^{(19)}$ os polifenois apresentam elevada solubilidade em acetato de etila, o que faz com que essa fração apresente maior atividade antioxidante. Corroborando com essa afirmação, na marcha fitoquímica preliminar foram detectados flavonoides na fração acetato de etila. A literatura relata a presença de flavonoides e taninos nas frações acetato de etila e butanólica, como no trabalho de Silva et al. ${ }^{(20)}$ no qual foram isolados dois flavonoides das frações acetato de etila e butanólica do extrato bruto de Herissantia tiubae (K. Schum) Brizicky (Malvaceae).

capacidade sequestradora de radicais livres das frações acetato de etila e butanólica foi superior à da rutina, um flavonoide com reconhecida atividade. Esta avaliação se mostrou vantajoso em relação à técnica original, devido à redução nas quantidades de solventes, amostras e reagentes empregados.

Considerando os dados obtidos, é interessante aprofundar a investigação das atividades biológicas das folhas de Campomanesia xanthocarpa, especialmente procederem à avaliação da capacidade antioxidante in vivo e através de 
outras metodologias, além de realizar a elucidação estrutural de principais compostos isolados responsáveis por tal atividade.
Agradecemos ao CNPq pelo apoio financeiro que nos concedeu para a realização desse projeto. 0 trabalho deu origem a Monografia de Final de Curso da discente autora.

\section{AGRADECIMENTOS}

\section{REFERÊNCIAS}

1. Niero R, Malheiros A, Bittencourt CMS, Biavatti MW, Leite SN, Cechinel-Filho V. Aspectos químicos e biológicos de plantas medicinais e considerações sobre fitoterápicos. In: Bresolin TMB, Cechinel-Filho V. Ciências Farmacêuticas. Contribuição ao desenvolvimento de novos fármacos e medicamentos. Itajaí: Univali, 2003. p. 10-56.

2. Veiga Junior VF, Pinto AC, Maciel MAM. Plantas medicinais: cura segura? Quím. Nova 2005; 28 (3): 519-528.

3. Biavatti MW, Farias C, Curtius F, Brasil LM, Hort S, Schuster L, Leite SN, Prado SR. Preliminary studies on Campomanesia xanthocarpa (Berg.) and Cuphea carthagenensis (Jacq.) J.F. Macbr. aqueous extract: weight control and biochemical parameters. J. Ethnopharm. 2004; 93 (2-3): 385-389.

4. Markman BEO, Bacchi EM, Kato ETM. Antiulcerogenic effects of Campomanesia xanthocarpa. J. Ethnopharm. 2004; 94 (1): 55-57.

5. Markman BEO. Caracterização farmacognóstica de Campomanesia xanthocarpa Myrtaceae [dissertation]. São Paulo: Faculdade de Ciências Farmacêuticas/USP; 2002. 169 p.

6. Schmeda-Hirschmann G. Flavonoids from Calycorectes, Campomanesia, Eugenia and Hexachlamys species. Fitoterapia 1995; 66: 373-374.

7. Li H, Hao Z, Wang X, Huang L, Li J. Antioxidant activities of extracts and fractions from Lysimachia foenum-graecum Hance. Bioresource Technology 2009; 100 (2): 970-974.

8. Yunes RA, Calixto JB. Plantas medicinais sob a ótica da química medicinal moderna. 1 ed. Chapecó: Argos; 2001.

9. Pharmacopoea Helvetica. 7 ed. Berne: Departament Féderal de I'Intérieur. 1995. 
10. SOUSA CMM, Silva HR, Vieira-Junior GM, Ayres MCC, COSTA CLS, ARAújo DS ET AL. FENÓIS TOTAIS E ATIVIDADE ANTIOXIDANTE DE CINCO PLANTAS MEDICINAIS. QUÍM. NOVA 2007; 30 (2): 351-355.

11. Gouvêa MR. Estudo Botânico e Fitoquímico de Campomanesia xanthocarpa Berg (Myrtaceae) [dissertation]. Curitiba: Setor de Ciências Biológicas/UFPR, 2001, 67 p.

12. Gobbo-Neto L, Lopes NP. Plantas medicinais: fatores de influência no conteúdo de metabólitos secundários. Quím. Nova 2007; 30 (2): 374-381.

13. Farmacopeia Brasileira: 5 ed. Volume 1 e 2. Agência Nacional de Vigilância Sanitária 2010. em: http://www.anvisa.gov.br/hotsite/cd_farmacopeia/index.htm.

14. Huang D, Ou B, Prior R. The chemistry behind antioxidant capacity assays. J. Agric. Food Chem. 2005; 53 (6): 1841-1856.

15. Duarte-Almeida JM, Santos RJ, Genovese MI, Lajolo MF. Avaliação da atividade antioxidante utilizando sistema $\beta$-caroteno-ácido linoleico e método de sequestro de radicais DPPH. Ciên. Tecnol. Aliment. 2006; 26 (2): 446-452.

16. Barbosa J. Campomanesia lineatifolia Ruiz e Pav.: estudo fitoquímico e avaliação da atividade antioxidante [dissertation]. Belo Horizonte: Faculdade de Farmácia/UFMG; 2009. 133p.

17. Coutinho ID, Kataoka VMF, Honda NK, Coelho RG, Vieira MC, Cardoso CAL. Influência da variação sazonal nos teores de flavonoides e atividade antioxidante das folhas de Campomanesia adamantium (Cambess.) O. Berg, Myrtaceae. Rev. Bras. Farmacogn. 2010; 20 (3): 322-327.

18. Cardoso CAL, Silva JRM, Kataoka VMF, Brum CS, Poppi NR. Avaliação da atividade antioxidante, toxicidade e composição química por CG-MS do extrato hexânico das folhas de Campomanesia pubens. Rev. Ciênc. Farm. Básica Apl. 2008; 29 (3): 297-301.

19. Andrade CA, Costa CK, Bora K, Miguel MD, Miguel OG, Kerber VA. Determinação do conteúdo fenólico e avaliação da atividade antioxidante de Acacia podalyriifolia A. Cunn. ex G. Don, Leguminosae-mimosoideae. Rev. Bras. Farmacogn. 2007; 17 (2): 231-235.

20. Silva DA, Costa DA, Silva DF, Souza MFV, Agra MF, Medeiros IA et al. Flavonoides glicosilados de Herissantia tiubae (K. Schum) Brizicky (Malvaceae) e testes farmacológicos preliminares do canferol 3,7-di-O-a-L-ramnopiranosídeo. Rev. Bras. Farmacogn. 2005; 15 (1): 23-29. 